\title{
Morphometric properties of the tensor fascia lata muscle in human foetuses
}

\author{
O. Beger ${ }^{1}$, T. Koç${ }^{1}$, B. Beger ${ }^{2}$, D. Uzmansel ${ }^{1}$, Z. Kurtoğlu ${ }^{1}$ \\ ${ }^{1}$ Department of Anatomy, Mersin University Faculty of Medicine, Mersin, Turkey \\ ${ }^{2}$ Department of Paediatric Surgery, Faculty of Medicine, Van Yüzüncü Yıl University, Van, Turkey
}

[Received: 27 December 2017; Accepted: 4 January 2018]

\begin{abstract}
Background: In neonatal and early childhood surgeries such as meningomyelocele repairs, closing deep wounds and oncological treatment, tensor fasciae lata (TFL) flaps are used. However, there are not enough data about structural properties of TFL in foetuses, which can be considered as the closest to neonates in terms of sampling. This study's main objective is to gather data about morphological structures of TFL in human foetuses to be used in newborn surgery.

Materials and methods: Fifty formalin-fixed foetuses (24 male, 26 female) with gestational age ranging from 18 to 30 weeks (mean $22.94 \pm 3.23$ weeks) were included in the study. TFL samples were obtained by bilateral dissection and then surface area, width and length parameters were recorded. Digital callipers were used for length and width measurements whereas surface area was calculated using digital image analysis software.

Results: No statistically significant differences were found in terms of numerical value of parameters between sides and sexes $(p>0.05)$. Linear functions for TFL surface area, width, anterior and posterior margin lengths were calculated as $y=-225.652+14.417 \times$ age (weeks), $y=-5.571+0.595 \times$ age (weeks), $y=-4.276+0.909 \times$ age $($ weeks), and $y=-4.468+0.779 \times$ age $($ weeks), respectively. Conclusions: Linear functions for TFL surface area, width and lengths can be used in designing TFL flap dimensions in newborn surgery. In addition, using those described linear functions can also be beneficial in prediction of TFL flap dimensions in autopsy studies. (Folia Morphol 2018; 77, 3: 498-502)
\end{abstract}

Key words: tensor fascia lata, linear functions, surface area, foetus

\section{INTRODUCTION}

Tensor fascia lata (TFL), a muscle in gluteal region, originates from the outer lip of the iliac crest, the anterolateral iliac fossa just below the iliac crest, the deep surface of the fascia lata, the iliac tubercle, the lateral aspect of the anterior superior iliac spine and a notch below the anterior superior iliac spine. TFL attaches to two layers of the iliotibial tract of the fascia lata and ends usually around the greater trochanter.
It assists the medial rotation and abduction of thigh in addition to lateral rotation of leg by iliotibial tract $[11,12,15,27]$.

Flaps of TFL, which is short and straight, are not only widely used in a large number of applications in adults $[6,15,19-21,26]$, but also in early childhood surgeries as well $[1,20,22]$. Some of the applications where musculocutaneous or free-form flaps of TFL are used can be summarised as burn treatments [1], chest

Address for correspondence: Dr. O. Beger, Mersin University Faculty of Medicine, Department of Anatomy, Ciftlikkoy Campus, 33343, Mersin, Turkey, tel: +90 3243610683/1092, fax: +90 324 3412400, e-mail: obeger@gmail.com 

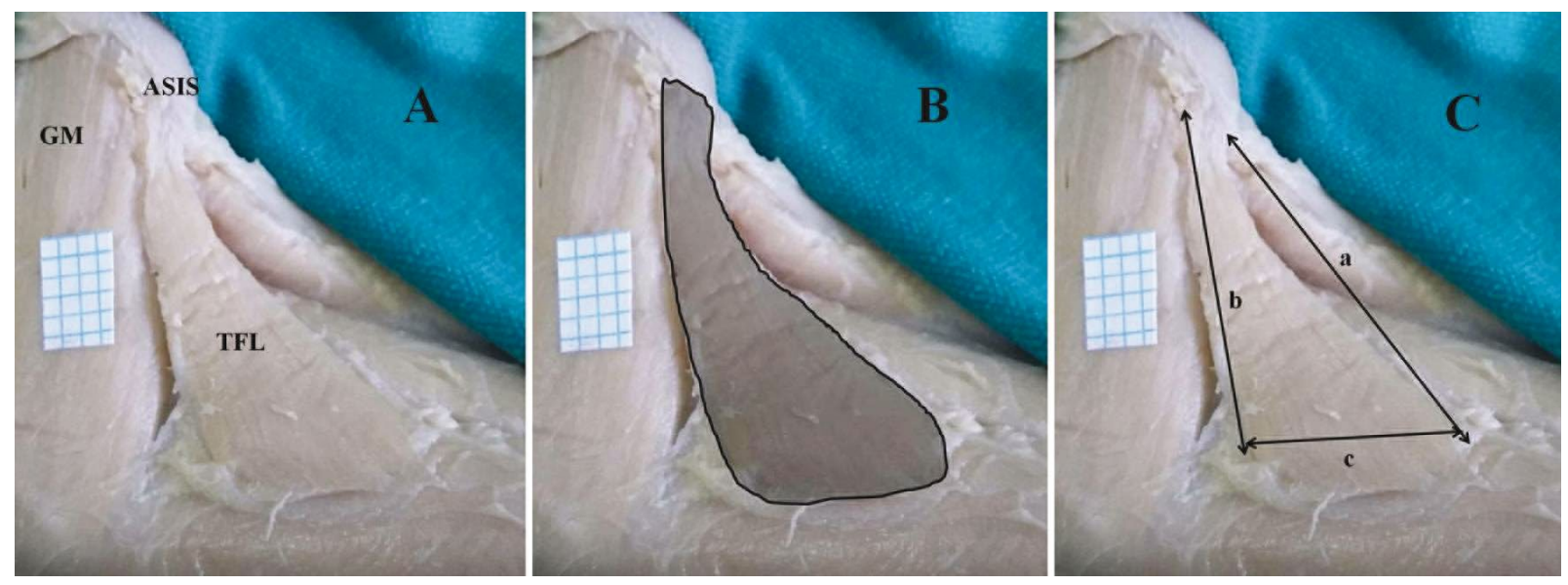

Figure 1. Tensor fascia lata (TFL) and measured parameters; A. TFL with millimetric scale; B. TFL surface area; C. TFL parameters: a - anterior margin; $b$ - posterior margin; $c$ — width (at widest level); ASIS — anterior superior iliac spine; GM — gluteus medius muscle.

and abdominal wall reconstruction $[6,21]$, correcting defects in head-neck region $[3,5,9]$, treatment of oncology patients [7, 10, 24], meningomyelocele repair [22, 23], and correction of functional disorders of upper or lower extremities $[16,28]$.

In the literature, data about TFL structural properties in foetuses, which can be considered as the closest in resemblance to neonates, is quite limited. Our study's main objective is to define morphometric properties of TFL in foetal period and its growth dynamics to be used in neonatal surgery.

\section{MATERIALS AND METHODS}

Fifty foetuses ( 24 male, 26 female) with gestational age range from 18 to 30 weeks (mean $22.94 \pm 3.23$ weeks) present in Mersin University Faculty of Medicine Anatomy Department were included in the study and bilateral dissection was performed in each sample. Between 2000 and 2005, foetuses were donated to our department. There were limited documentary of the cause of death of foetuses. Therefore, foetuses with structural defects were excluded from this study. They were preserved in $10 \%$ formalin solution for more than 12 years. The study was approved by the Ethics Board of Medicine Faculty (2017/313). After positioning the foetuses in lateral decubitis, skin and fascias were lifted. TFL was exposed by microscope-aided (Carl Zeiss f-170) dissection. The following parameters were recorded (Fig. 1):

- TFL surface area;

- TFL lengths of the anterior and posterior margin (the distance between its origin and insertion);

- TFL width (at its widest level);

- TFL proximal attachment sites and attachment levels to iliotibial tract in distal plane.
As the reduction of plasticity was reported as $0.5-$ $-1 \%$ in the previous studies $[8,14]$, tissue shrinkage caused by formalin fixation was disregarded. All samples were photographed from the same distance in the same position with millimetric scales (LG) and surface area was calculated using digital image analysis software (Digimizer Software). The length and width parameters were measured using digital callipers with $0.01 \mathrm{~mm}$ precision. All the parametric measurements were performed by the same researcher (O.B.) under same conditions in three different dates and the mean value of measurements were calculated. One-way ANOVA test, post-hoc RIR Tukey tests and intra-class correlation coefficients (ICC) were used to assess intra-observer reproducibility. Gestational age was determined by measuring foot lengths according to Malas et al.'s study [18]. Normality controls were performed with the Shapiro-Wilk test. Gestational age (months) was used in comparison of sides and sexes. Paired sample t-test was used for comparing sides and independent sample-t test was used to compare sexes. Homogeneity of variances was tested using Levene test. One-way ANOVA and Bonferroni tests were used to compare the changes with gestational age (months) in surface area and morphometric data on length and width. Simple linear regression analysis was used to calculate the regression equations which showed the relationship of changes in morphometric data with respect to gestational age (weeks). Statistical significance level was set as $p<0.05$.

\section{RESULTS}

Table 1 summarises the demographic values of foetuses included in the study. All sides had TFL (Fig. 1). 
Table 1. Data related to age, number and sex of foetuses

\begin{tabular}{|c|c|c|c|c|c|}
\hline \multicolumn{2}{|c|}{ Gestational age } & \multirow[t]{2}{*}{ Foot length [mm] } & \multirow[t]{2}{*}{ Number of side } & \multicolumn{2}{|c|}{ Number of sexes } \\
\hline Months & Weeks & & & Male & Female \\
\hline \multirow[t]{3}{*}{ V } & 18 & $25.55 \pm 0.28$ & 6 & 2 & 1 \\
\hline & 19 & $27.98 \pm 0.27$ & 8 & 2 & 2 \\
\hline & 20 & $30.72 \pm 0.26$ & 14 & 1 & 6 \\
\hline \multirow[t]{4}{*}{$\mathrm{Vl}$} & 21 & $32.80 \pm 0.20$ & 10 & 2 & 3 \\
\hline & 22 & $34.50 \pm 0.30$ & 12 & 5 & 1 \\
\hline & 23 & $38.65 \pm 0.33$ & 12 & 2 & 4 \\
\hline & 24 & $40.71 \pm 0.36$ & 8 & 3 & 1 \\
\hline \multirow[t]{4}{*}{ VII } & 25 & $41.89 \pm 0.49$ & 6 & 2 & 1 \\
\hline & 26 & $45.56 \pm 0.36$ & 6 & 1 & 2 \\
\hline & 27 & $48.42 \pm 0.44$ & 8 & 2 & 2 \\
\hline & 28 & $52.01 \pm 0.28$ & 4 & 1 & 1 \\
\hline \multirow[t]{2}{*}{ VIII } & 29 & $53.30 \pm 0.11$ & 2 & 1 & 0 \\
\hline & 30 & $54.57 \pm 0.59$ & 4 & 0 & 2 \\
\hline Total & & & 100 & 24 & 26 \\
\hline
\end{tabular}

Table 2. Morphometric data related to tensor fascia lata considering the gestational months

\begin{tabular}{lcccccc}
\hline Parameters & $\begin{array}{c}\text { V month } \\
(\mathbf{n = 2 8})\end{array}$ & $\begin{array}{c}\text { VI month } \\
(\mathbf{n}=\mathbf{4 2})\end{array}$ & $\begin{array}{c}\text { VII month } \\
(\mathbf{n = 2 4 )}\end{array}$ & $\begin{array}{c}\text { VIII month } \\
(\mathbf{n}=\mathbf{6})\end{array}$ & $\begin{array}{c}\text { Total } \\
(\mathbf{n}=\mathbf{1 0 0})\end{array}$ & $\mathbf{p}$ \\
\hline Surface area $\left[\mathrm{mm}^{2}\right]$ & $58.45 \pm 19.35$ & $94.14 \pm 22.46$ & $150.92 \pm 33.19$ & $215.75 \pm 17.71$ & $105.07 \pm 50.01$ & $<0.001$ \\
Length of anterior margin $[\mathrm{mm}]$ & $13.09 \pm 2.67$ & $16.24 \pm 2.15$ & $19.45 \pm 2.94$ & $19.58 \pm 1.37$ & $16.57 \pm 3.69$ & $<0.001$ \\
Length of posterior margin $[\mathrm{mm}]$ & $10.70 \pm 2.81$ & $12.89 \pm 2.38$ & $16.37 \pm 2.67$ & $17.58 \pm 1.58$ & $13.39 \pm 3.41$ & $<0.001$ \\
Width (the its widest level) $[\mathrm{mm}]$ & $5.95 \pm 1.28$ & $7.85 \pm 1.68$ & $9.91 \pm 0.96$ & $12.06 \pm 0.71$ & $8.06 \pm 2.22$ & $<0.001$ \\
\hline
\end{tabular}

No statistically significant difference was found in the assessment of intra-observer reproducibility of numerical values of TFL ( $p>0.05)$. In addition, ICC score for TFL parameters was calculated as ICC 0.996-0.999 ( $p<0.001$ ) which shows an excellent intra-observer reproducibility. As TFL surface area, width and length did not show a statistically significant difference between the sides and sexes ( $p>0.05)$, numerical values were summarised in Table 2 , according to gestational months. Figures 2 and 3 present the regression graphs and equations which show the parameter changes with gestational weeks. Linear functions for TFL surface area, width, anterior and posterior margin lengths were calculated as $y=-225.652+14.417 \times$ age (weeks), $y=-5.571$ $+0.595 \times$ age (weeks), y $=-4.276+0.909 \times$ age (weeks) and $y=-4.468+0.779 \times$ age (weeks), respectively. Anterior margin of TFL was found to be longer than posterior margin $(p<0.001)$. TFL attached to the lateral aspect of the anterior superior iliac spine and a notch below it by tendinous fibres and the deep surface of fascia lata in proximal plane. In distal plane, TFL joined iliotibial tract under greater trochanter on the upper $1 / 3$ area of thigh.

\section{DISCUSSION}

In this study, we obtained precious data regarding the morphometric properties of TFL in foetuses to be used in neonatal surgery, which is quite limited in the literature. We revealed the algebraic change of TFL in foetuses between $18^{\text {th }}$ and $30^{\text {th }}$ weeks of gestational age.

Tensor fascia lata flaps are used in closing deep wounds, meningomyelocele repairs and treatment of oncology patients during the early term of life [7, 20, 22-24]. Akyürek and Şafak [1] treated a 12-monthold male with a burn on his right arm using TFL flap. Ohno et al. [20] used TFL flap in treatment of rhabdomyosarcoma in pelvic region in a 10-month-old male patient and reported no complications or function loss. Phillips and Lindseth [22] retrospectively reviewed 47 meningomyocele patients with a mean age of 4.6 years and reported that 41 were treated 

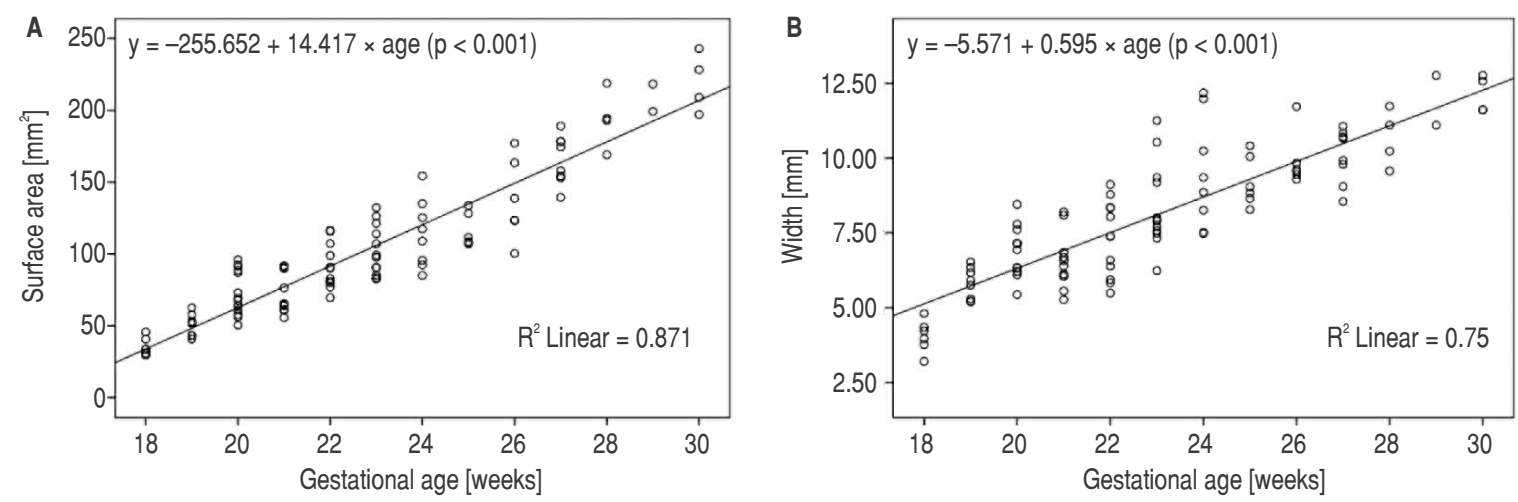

Figure 2. Linear regression lines; A. Tensor fascia lata (TFL) surface area; B. The width of TFL.
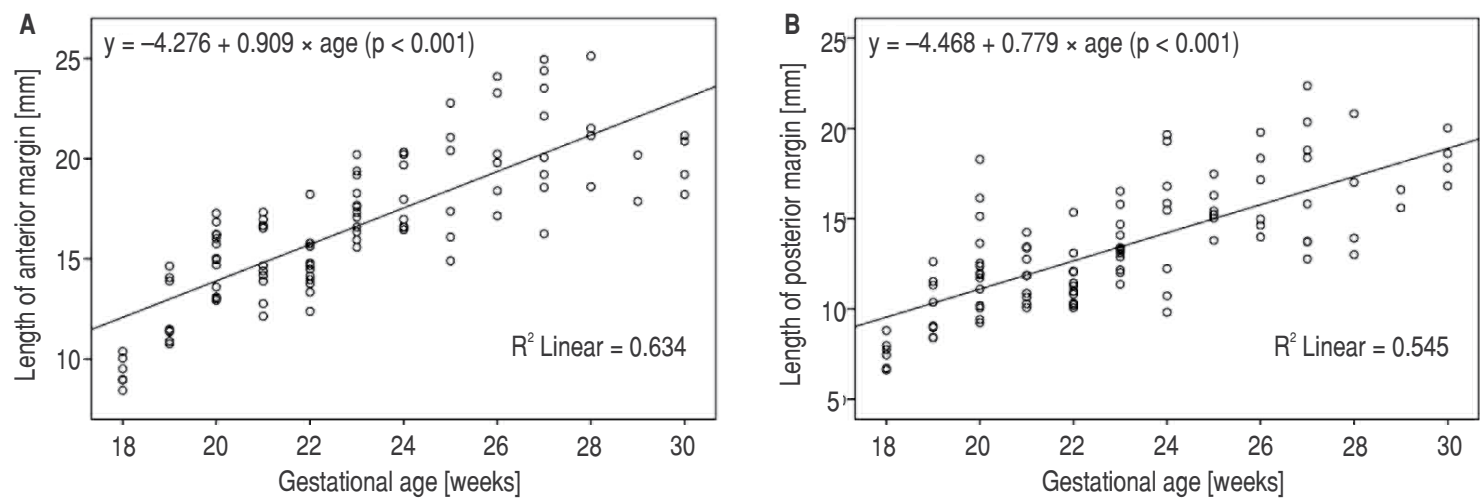

Figure 3. Linear regression lines; A. Length of anterior margin; B. Length of posterior margin.

using the external oblique, the adductors and TFL (triple transfer) method. However, the authors also reported that the remaining 6 patients were treated with a double transfer of the external obliques and the adductors due to insufficient TFL tissue [22]. Since it's known that burns, congenital malignant tumours or meningomyelocele can be seen during neonatal period and TFL flaps can be used in the treatment of those conditions $[10,22,23]$, the importance of defining algebraic anatomy and variations of TFL becomes clear for neonatal surgery. In our study, TFL was present in all sides without any exceptions. As the numerical data of TFL showed no statistically significant difference between sides, TFL flaps on both sides can be used in treatment of conditions where TFL free tissue flaps are used. As expressed in Beger et al.'s study [4] on latissimus dorsi muscle, TFL regression equations can be used in designing TFL flap dimensions, especially in treatment of conditions such as meningomyelocele.
Although literature reported a number of differences in many muscle growth dynamics between foetuses $[2,4,13,14,17,25]$, no quantitative studies on TFL were found. In accordance with the previous study results on morphometric properties of different muscle groups $[2,4,13,14,17]$, this study revealed a rational increase in numerical values of TFL surface area, width and lengths from $18^{\text {th }}$ to $30^{\text {th }}$ week and showed no statistically significant difference between sides and sexes.

Proximal and distal attachment points of TFL show variety $[11,12,15,27]$. In our study, we showed that TFL originates from the deep surface of the fascia lata and lateral aspect of the anterior superior iliac spine and a notch below it in proximal plane by tendinous fibres. In distal plane, TFL joined iliotibial tract under greater trochanter on the upper $1 / 3$ area of thigh. Our data related to attachment points of TFL showed greatly coherent with previous studies $[11,12,15,27]$. 


\section{CONCLUSIONS}

The algebraic values of TFL surface area, width and lengths showed a rational increase from $18^{\text {th }}$ to $30^{\text {th }}$ week and no statistically significant difference between sides and sexes. Linear function of surface area, which was calculated as " $y=-225.652$ $+14.417 \times$ age (weeks)", can be used in designing TFL flap dimensions in neonatal surgeries. Using linear functions to approximate TFL flap dimensions can be beneficial in autopsy studies.

\section{REFERENCES}

1. Akyürek M, Safak T. Transfer of a free flap from an acutely burned donor site. Scand J Plast Reconstr Surg Hand Surg. 2004; 38(6): 370-372, indexed in Pubmed: 15841806.

2. Badura M, Grzonkowska M, Baumgart M, et al. Quantitative Anatomy of the Trapezius Muscle in the Human Fetus. Adv Clin Exp Med. 2016; 25(4): 605-609, indexed in Pubmed: 27629832.

3. Baker SR. Reconstruction of mandibular defects with the revascularized free tensor fascia lata osteomyocutaneous flap. Arch Otolaryngol. 1981; 107(7): 414-418, indexed in Pubmed: 7247803.

4. Beger O, Beger B, Uzmansel D, et al. Morphometric properties of the latissimus dorsi muscle in human fetuses for flap surgery. Surg Radiol Anat. 2017 [Epub ahead of print], doi: 10.1007/s00276-017-1946-4, indexed in Pubmed: 29143863.

5. Cheng $N$, Shou B, Zheng $M$, et al. Microneurovascular transfer of the tensor fascia lata musculocutaneous flap for reconstruction of the tongue. Ann Plast Surg. 1994; 33(2): 136-141, indexed in Pubmed: 7979043.

6. Chevray PM, Singh NK. Abdominal wall reconstruction with the free tensor fascia lata musculofasciocutaneous flap using intraperitoneal gastroepiploic recipient vessels. Ann Plast Surg. 2003; 51(1): 97-102, doi: 10.1097/01.SAP.0000041478.74885.19, indexed in Pubmed: 12838132.

7. Chitale VR. Role of tensor fascia lata musculocutaneous flap in lymphedema of the lower extremity and external genitalia. Ann Plast Surg. 1989; 23(4): 297-304; discussion 305, indexed in Pubmed: 2817711.

8. Cutts A. Shrinkage of muscle fibres during the fixation of cadaveric tissue. J Anat. 1988; 160: 75-78, indexed in Pubmed: 3253263.

9. Demirkan F, Chen HC, Wei FC, et al. The versatile anterolateral thigh flap: a musculocutaneous flap in disguise in head and neck reconstruction. Br J Plast Surg. 2000; 53(1): 30-36, doi: 10.1054/bjps.1999.3250, indexed in Pubmed: 10657446.

10. Enam SF, Waqas $M$, Rauf MY, et al. Congenital malignant melanoma of the scalp in a 25-day-old neonate. BMJ Case Rep. 2014; 2014, doi: 10.1136/bcr-2013-202588, indexed in Pubmed: 24759603.

11. Flack NA, Nicholson HD, Woodley SJ. A review of the anatomy of the hip abductor muscles, gluteus medius, gluteus minimus, and tensor fascia lata. Clin Anat. 2012; 25(6): 697-708, doi: 10.1002/ca.22004, indexed in Pubmed: 22109658

12. Flack N, Nicholson HD, Woodley SJ. The anatomy of the hip abductor muscles. Clin Anat. 2013; 27(2): 241-253, doi: $10.1002 / c a .22248$.
13. Grzonkowska M, Badura M, Lisiecki J, et al. Growth dynamics of the triceps brachii muscle in the human fetus. Adv Clin Exp Med. 2014; 23(2): 177-184, indexed in Pubmed: 24913107.

14. Grzonkowska M, Baumgart M, Badura M, et al. Quantitative anatomy of the growing quadratus lumborum in the human foetus. Surg Radiol Anat. 2018; 40(1): 91-98, doi: 10.1007/s00276-017-1901-4, indexed in Pubmed: 28756538.

15. Hill HL, Nahai F, Vasconez LO. The tensor fascia lata myocutaneous free flap. Plast Reconstr Surg. 1978; 61(4): 517-522, indexed in Pubmed: 345303.

16. Karagöz H, Öksüz S, Ülkür $E$, et al. Definitive foot drop deformity repair with tensor fascia latae myocutaneous flap. Microsurgery. 2013; 33(3): 223-226, doi: 10.1002/ micr.22065, indexed in Pubmed: 23280681.

17. Kędzia A, Janeczko M, Miśkiewicz K, et al. Morphometry of human musculus gluteus maximus in foetal period. Adv Clin Exp Med. 2014; 23(1): 9-16, indexed in Pubmed: 24595998.

18. Malas MA, Desdicioglu K, Cankara N, et al. Fetal dönemde fetal yaşın belirlenmesi. S D Ü Tıp Fak Derg. 2007; 14(1): 20-24.

19. Nahai F, Silverton JS, Hill HL, et al. The tensor fascia lata musculocutaneous flap. Ann Plast Surg. 1978; 1(4): 372-379, indexed in Pubmed: 365059.

20. Ohno Y, Tanaka K, Kanematsu T, et al. Reconstruction of a pelvic floor defect using a pedicled tensor fascia lata flap: a new technique to prevent radiation injury for pediatric patients with advanced pelvic tumors. J Pediatr Surg. 2008; 43(5): 947-950, doi: 10.1016/j.jpedsurg.2007.12.040, indexed in Pubmed: 18485975.

21. Ono J, Takeda $A$, Akimoto $M$, et al. Free tensor fascia lata flap and synthetic mesh reconstruction for fullthickness chest wall defect. Case Rep Med. 2013; 2013: 914716, doi: 10.1155/2013/914716, indexed in Pubmed: 24191162.

22. Phillips DP, Lindseth RE. Ambulation after transfer of adductors, external oblique, and tensor fascia lata in myelomeningocele. J Pediatr Orthop. 1992; 12(6): 712-717, indexed in Pubmed: 1452737.

23. Posma AN. The innervated tensor fasciae latae flap in patients with meningomyelocele. Ann Plast Surg. 1988; 21(6): 594-596, indexed in Pubmed: 3239938.

24. Saito A, Minakawa $\mathrm{H}$, Saito $\mathrm{N}$, et al. Clinical experience using a tensor fascia lata flap in oncology patients. Surg Today. 2014; 44(8): 1438-1442, doi: 10.1007/s00595-0130733-z, indexed in Pubmed: 24065194.

25. Shiraishi Y, Jin ZW, Mitomo K, et al. Foetal development of the human gluteus maximus muscle with special reference to its fascial insertion. Folia Morphol. 2018; 77(1): 144-150, doi: 10.5603/FM.a2017.0060, indexed in Pubmed: 28653302.

26. Siddiqui $A$, Wiedrich $T$, Lewis VL. Tensor fascia lata V-Y retroposition myocutaneous flap: clinical experience. Ann Plast Surg. 1993; 31(4): 313-317, indexed in Pubmed: 8239429.

27. Standring S, Borley NR, Collins P, et al. Gray's anatomy: the anatomical basis of clinical practice. 40th Ed. Elsevier: Churchill Livingstone, London. 2008.

28. Yagi $Y$, Ueda $K$, Shirakabe $M$, et al. Reconstruction of knee ligaments with a free tensor fascia lata myocutaneous flap transfer. Br J Plast Surg. 2002; 55(2): 155-157, doi: 10.1054/bjps.2001.3780, indexed in Pubmed: 11987953. 